\title{
Performance of neural networks in materials science
}

\author{
H. K. D. H. Bhadeshia*1,2 , R. C. Dimitriu1, S. Forsik ${ }^{1}$, J. H. Pak ${ }^{2}$ and J. H. Ryu ${ }^{2}$
}

Neural networks are now a prominent feature of materials science with rapid progress in all sectors of the subject. It is premature, however, to claim that the method is established. There are genuine difficulties caused by the often incomplete exploration and publication of models. The assessment presented here is an attempt to compile a loose set of guidelines for maximising the impact of any models that are created, in order to encourage thoroughness in publication to a point where the work can be independently verified.

Keywords: Neural network, Materials science, Materials modelling, Uncertainties, Errors

\section{Introduction}

Neural networks have proved to be powerful and popular in dealing with complex problems of the type typical in materials science. ${ }^{1-6}$ Indeed, as pointed out by Abrahart et al., ${ }^{7}$ aside from materials science, there are reviews or extended summaries of the applications of networks in the fields of hydrological sciences, ${ }^{8}$ atmospheric sciences, ${ }^{9}$ civil engineering, ${ }^{10}$ process engineering $^{11}$ and structural engineering. ${ }^{12}$ This reflects the generic nature of the method.

However, the way in which the method is applied varies widely and it would be useful to assess the advantages and disadvantages of the different approaches and the way in which the results are presented and published. It has previously been pointed out, when discussing neural networks in the hydrosciences, ${ }^{8}$ that in many cases the model building process is described poorly, making it difficult to assess the optimality of the results obtained. The purpose here is to assess the value of neural networks published in the context of materials science. The authors begin by describing the basic principles of such networks in order to highlight aspects which increase the generic value of the networks and related publications. Details of the neural network method itself are available elsewhere, for example. $^{1-4,8,9}$

There are many methods for creating a neural network model, but the essential principles are as follows. A complicated problem is identified in which the relationships between the dependent and independent variables are not clear, although simple qualitative trends may be understood. It is sometimes the case that these trends may be justified by analytical expressions which are scientifically rigorous but limited in their scope. One example is the irradiation hardening of steels

${ }^{1}$ Materials Science and Metallurgy, University of Cambridge, Cambridge CB2 3QZ, UK

${ }^{2}$ Graduate Institute of Ferrous Technology (GIFT), Pohang University of Science and Technology (POSTECH), Pohang 790-784, Korea

*Corresponding author, email hkdb@cam.ac.uk in which it is obvious that the defects introduced by radiation damage must contribute to strength, but it is not at all clear how the myriad of solutes present in the steel influence the extent of hardening. ${ }^{13}$ It is known that thermal activation plays a role in the accumulation of hardening defects, and it can reasonably be assumed that this manifests via an Arrhenius term $\exp (-Q / k T)$. But the detailed effect of temperature is not fully represented by this 'rigorous' parameter, since other influences, such as the solubility of species under a neutron flux, also depend on temperature and other factors.

Once the problem is defined, the data are compiled into a set which is used to create a non-linear regression or classification model in the form of a neural network. The process does not at the outset require an assumption of the form of the relationship: the latter is discovered during the training procedure. The final model is a mathematically transparent set consisting of the function and the coefficients needed to implement the function.

\section{Purpose}

It is appropriate to attempt neural network analysis when the problem presented is so complex that a rigorous treatment is impossible and yet, a quantitative treatment is needed. Consider for example, fracture; there exist the well defined concepts of fracture mechanics with clear relationships between stress and crack dimensions through a parameter known as 'fracture toughness'. The toughness can be measured and used in engineering design. But access to a comprehensive description of the chemical composition, processing parameters and structure of a material, does not enable the toughness to be predicted. In other words, there is no way of using the theory of fracture mechanics to quantitatively design a material with a specified resistance to brittle fracture.

On the other hand, there exist vast quantities of fracture toughness data as a function of many variables from the myriad of quality control and research 
experiments. These experimental data can be assembled and investigated by creating a neural network model. The advantage is that the effect of large numbers of input variables can be studied and visualised quantitatively. At the same time, it is possible to account for arbitrary interactions between the variables, thus revealing trends which differ according to the position in the input space where calculations are carried out. This kind of exploration of the relationships is simply not possible in qualitative analysis or when the problem is reduced to fewer variables. It is immensely satisfying to be able to discover fundamental relationships and structure within vast arrays of ill understood data.

To summarise, the purpose of neural network analysis is to enable the quantitative expression and understanding of very complicated problems.

\section{Uncertainty}

It is particularly important to consider two kinds of error when the performance of neural networks is assessed.

Noise results in a different output for the same set of inputs when the experiment is repeated. This is because there are variables which are not controlled so their influence is not included in the analysis. Suppose that a model has been created in such a way that overfitting has been avoided (neural networks are so powerful that they can in principle predict the data on which they have been trained, perfectly (zero noise), even when this is not justified. Procedures are therefore used to avoid fitting to noise in the data, see, for example, Refs. 2 and 4). The noise in the output can be assessed by comparing the predicted values $y_{\mathrm{j}}$ of the output using this well fitted network, against those measured $t_{\mathrm{j}}$, for example,

$$
E_{\mathrm{D}} \propto \sum_{\mathrm{j}}\left(t_{\mathrm{j}}-y_{\mathrm{j}}\right)^{2}
$$

$E_{\mathrm{D}}$ should be expected to increase if important input variables have been excluded from the analysis.

Notice that however this noise is measured, it is a constant value. It does not help much in assessing the behaviour of the model when extrapolating.

It is necessary particularly with neural networks, to consider a second kind of uncertainty, which is due to the modelling itself. It is likely in complex problems that there may exist many mathematical functions which adequately represent the same set of empirical data but which behave differently in extrapolation. This difference in behaviour is characterised by a modelling uncertainty. Figure 1 illustrates how a number of different mathematical functions might adequately represent the same data in the region designated, but which behave differently in regions where data are sparse or noisy. In the regions designated as 'A', the modelling uncertainty is clearly large with a lot of variance in the predictions of different functions. In contrast, there is general agreement between the different functions in the region designated 'B', where data exist and the calculations might be more reliable.

Unlike the noise, the magnitude of the modelling uncertainty is not constant, but varies as a function of position in the input space. It is an excellent way of identifying domains where further experiments are needed to reduce uncertainty or where the predictions

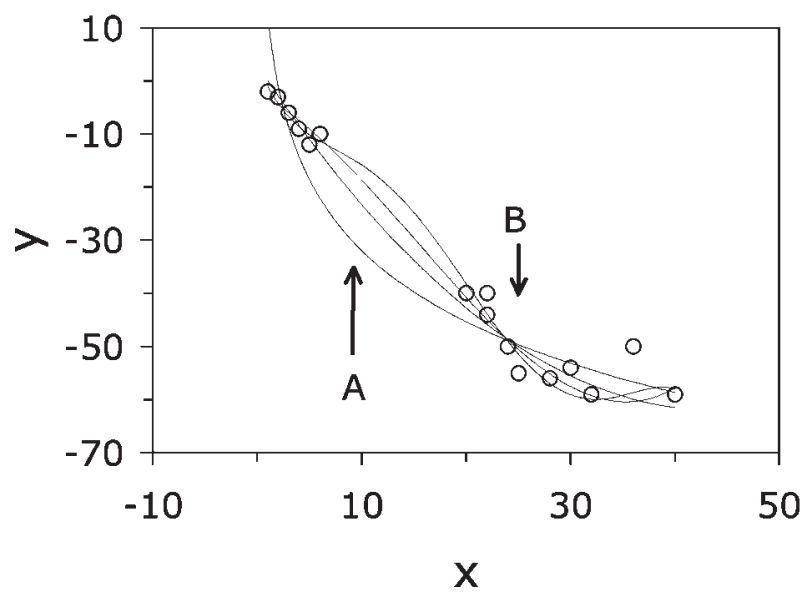

1 Illustration of how number of different functions might adequately represent same set of known data

should be used alongside an assessment based on other techniques, known trends or experience, but always with the insight given by the modelling uncertainty that calculations are being carried out in a region where knowledge is sparse.

The implication here is that it is not good practice to simply create a best fit model which while avoiding overfitting, minimises noise. ${ }^{2}$ A single model like this cannot indicate the dangers of extrapolation as embodied in the modelling uncertainty.

\section{Exploration}

A neural network is a clearly defined and transparent combination of a mathematical function and associated coefficients; there is nothing 'black box' about the technique as is sometimes implied. Indeed, the mathematical framework could not be simpler. A complete description of a typical network with $i$ hidden units, connecting the inputs $x_{\mathrm{j}}$ to the output $y$ is given by

$$
y=\sum_{\mathrm{i}} w_{\mathrm{i}}^{(2)} h_{\mathrm{i}}+\theta^{(2)}
$$

where

$$
h_{\mathrm{i}}=\tanh \left[\sum_{\mathrm{j}} w_{\mathrm{ij}}^{(1)} x_{\mathrm{j}}+\theta_{\mathrm{i}}^{(1)}\right]
$$

where $w$ and $\theta$ represent weights. Neural networks are useful because they are non-linear. This necessarily makes the weights more difficult to interpret when compared, for example, with the coefficients associated with linear regression equations. Neural networks routinely capture high order interactions between the variables which are difficult to visualise from an examination of the weights. This visualisation problem is a feature of all non-linear methods, but is not a limitation because it is simple to use the trained network to make predictions, plot them, and to see how these depend on various combinations of inputs.

Indeed, an exploration of the behaviour of the network is essential to understand whether the known physics of the problem has been captured correctly. The exploration must also include extrapolation beyond the data used to create the network, to see whether new discoveries can be made. The term 'prediction' as used in this paper refers particularly to the use of networks in 


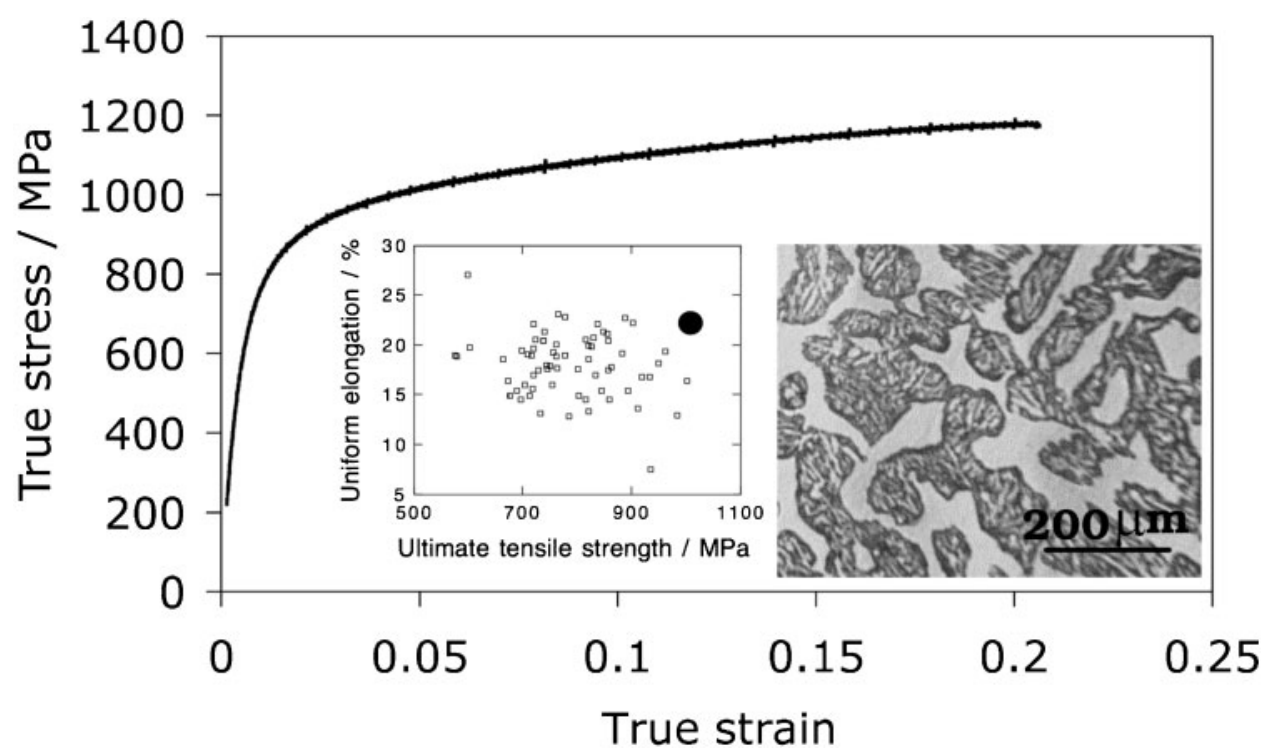

2 Properties and microstructure of $\delta$-TRIP steel: ${ }^{15}$ inset on left compares its properties (large dot) against published data on ordinary TRIP assisted steels

extrapolation. No distinction is necessary in this context between extrapolation and interpolation, since both terms refer to calculations in domains where the data on which the network is created are absent.

\section{Dissemination}

A great deal of scientific work is published in the form of research papers which describe the problem, the method and the outcomes, usually in sufficient detail to enable the work to be reproduced. Research involving neural network models is similarly published but the work cannot be independently reproduced from the publication alone, because as will be seen later, neither the data on which the model was created nor the coefficients needed to reproduce the mathematical structure of the network are available. A reader in general has to take the work on trust, which clearly is not satisfactory from many points of view.

This problem is not of course unique to neural networks, but to most models which really heavily on numerical computations. Modern technology in the form of the World Wide Web provides an elegant solution in that the numerical model itself or the data can be archived and made available for scrutiny, as a supplement to the normal research paper.

There are many pathways through neural network models of complex phenomena, making it difficult to comprehensively explore its behaviour. Dissemination of the model itself has an additional advantage that it will be exposed to a much wider audience with the potential of applications not originally envisaged by the creators of the model.

In the absence of thorough dissemination, a paper describing a neural network has rather limited use. It is of course a bonus for the authors in terms of the visibility of their work; the publication will also contain information about the approach and the problem being tackled, which has the potential of being qualitatively useful. However, any judgements must be made without the ability to conduct calculations.
The ideal scenario would be to publish the paper in the normal way and to make the model freely accessible on the World Wide Web.

\section{Experimental validation}

Mathematical models in materials science fall into the following categories: ${ }^{14}$

(i) those which lead to an unexpected outcome that can be verified

(ii) those which are created or used in hindsight to explain diverse observations

(iii) existing models which are adapted or grouped to design materials or processes

(iv) models used to express data, reveal patterns, or for implementation in control algorithms.

Most neural networks fall comfortably into the last category, but as can be seen later, they are not limited to that category. There are a few examples of new materials emerging from neural network analysis and discovery of a new phase. These latter achievements come from experiments designed specifically to test network behaviour in domains where data do not exist.

\section{Category 1 example}

One case where neural network analysis has led to a novel concept is illustrated in Fig. 2. Ordinary TRIP assisted steels contain a microstructure which is predominantly allotriomorphic ferrite with the remainder being carbide free bainite and carbon enriched retained austenite. The latter undergoes martensitic transformation during deformation which prolongs the ability of the steel to work harden, thus delaying plastic instabilities. At the same time, the martensite strengthens the microstructure. Silicon is a vital element in these steels, in concentrations which are typically greater than $1 \mathrm{wt}-\%$, because it prevents the precipitation of cementite during the formation of upper bainite and hence allows the retention of austenite. A huge amount of research has been conducted on these steels; the subject is mature and the steels are commercially available and indeed used in the automobile industry. 
Silicon in the concentrations used can have undesirable consequences on the quality of the steel surface. For this reason, a neural network based on published data on ordinary TRIP assisted steels was created and combined with a genetic algorithm to see whether an alloy could be created with a low silicon concentration but which still retains the austenite. As a result, a novel concept in TRIP assisted steels was discovered, with a microstructure consisting of $\delta$-ferrite dendrites and a mixture of bainitic ferrite and carbon enriched retained austenite (Fig. 2). The steel has been manufactured and tested to reveal a tensile strength of about $1 \mathrm{GPa}$ and a uniform elongation of $23 \%{ }^{15}$

\section{Category 2 example}

The so called electrical steels are designed to be magnetically soft so that hysteresis effects are minimised. There are two essential classes of such steels, those which are crystallographically textured to optimise magnetic properties, and the cheaper varieties where the grains are not oriented. In the latter case, it was observed from a large number of commercial samples, that there were significant variations in magnetic permeability and power loss in spite of the fact that only the silicon concentration varied $(0 \cdot 04-0 \cdot 52 \mathrm{wt}-\%)$ between the samples, all of which had insignificant inclusion contents. ${ }^{16}$

The variations were imagined to be due to microstructure, so a neural network model was created with grain size, crystallographic texture and silicon as inputs. The necessary data were measured deliberately for the purposes of neural network modelling. Interesting nonlinear trends were discovered and interpreted, which explained, for example, the dependence of the optimum grain size on the silicon concentration.

\section{Category 3 example}

There has been considerable research on modelling heat and fluid flow during welding, one of the objectives of which is to predict the shape of the weld pool as a function of process parameters such as the welding current, voltage and speed. ${ }^{17}$ The methods are computer intensive and not practical enough to be applied in real time by welding engineers.

One solution would be to train a neural network on experimental data to reproduce the pool shape, with the inputs consisting of welding parameters. ${ }^{18}$ The inputs from three-wire submerged arc welds included plate thickness, preparation angle and depth, wire parameters (current, voltage angle, for three wires), speed, stickout and spacings between wires. The output was the entire weld bead profile.

Mishra and DebRoy ${ }^{19}$ adopted a different approach in which numerical heat and fluid flow calculations of weld geometry were used to train a neural network. The inputs consisted of variables used in the numerical calculations: arc characteristics (current, voltage, efficiency, radius, power distribution factor), welding speed, density, effective viscosity, effective thermal conductivity, solidus and liquidus temperatures, enthalpies at transformation temperatures, specific heats, thermal conductivity and the concentration of sulphur in steel (known to have an influence via the Marangoni effect). The output consisted of the weld penetration and width; these two parameters are in the model assumed to define the weld pool shape.
The trained network was then combined with a genetic algorithm to find the domain of inputs which would lead to the same pool shape, since the relationship between pool shape and inputs may not be unique within the limits of modelling error and the error in any validation experiments.

The assembly of three kinds of models to achieve a rapid algorithm for the solution of weld pool shape is original and has been demonstrated experimentally to reproduce weld pool shape. ${ }^{19}$

Mishra and DebRoy went on to claim that the input and output variables of the neural network model they created are consistent with the equations of conservation of mass, momentum and energy since the original database was generated using the heat and fluid flow models which embody these conditions. Whether this is the case remains to be demonstrated since the functional form of the neural network is independent of the conservation equations and the fitting of data is not in any case perfect. It is nevertheless true that a better network may result using as inputs, the same parameters that control the numerical heat and fluid flow models.

It would be interesting to investigate using the theory behind the heat and fluid flow models, whether it is in fact possible to obtain the same pool shape for different parameters. In other words, would a genetic algorithm be relevant unless there was imprecision in the neural network model?

There are in fact a number of other examples in the literature where physically based models are integrated with neural networks. For example, the work of Santos et al. in which a heat transfer model was combined with neural network based algorithms to improve the manufacturing strategy of the continuous casting of steel billets and blooms. ${ }^{20}$

\section{Category 4 example}

The precursor to a neural network analysis is the compilation of the necessary dataset. The data are often assembled from diverse published sources and the process itself is instructive in that it highlights the variables necessary to describe the outcome. For example, the creep rupture stress of steels has in neural network models been associated with some 50 variables in a dataset with more than 5000 experiments $^{21-25}$ and the Charpy toughness of weld metals with some 22 variables in a dataset consisting of more than 1900 experiments. $^{26-28}$

It is inconceivable that the influence of individual variables (let alone the interactions between variables) can be perceived in such complex databases by a qualitative analysis on it. Neural networks are wonderful tools for discovering patterns in precisely these circumstances.

One such discovery led to the recognition that weld metal Charpy toughness deteriorates when a steel containing a high manganese concentration is alloyed with nickel. This is contrary to the general impression in literature that nickel improves the toughness of ferritic steels. It turns out that for weld metals, this latter statement is only true when the manganese concentration is low, as illustrated in Fig. 3. This pattern was first recognised from a neural network model ${ }^{29}$ and the physical basis of the nickel-manganese interaction was explained in subsequent work. ${ }^{30-34}$ What happens is that in special circumstances when the difference between 


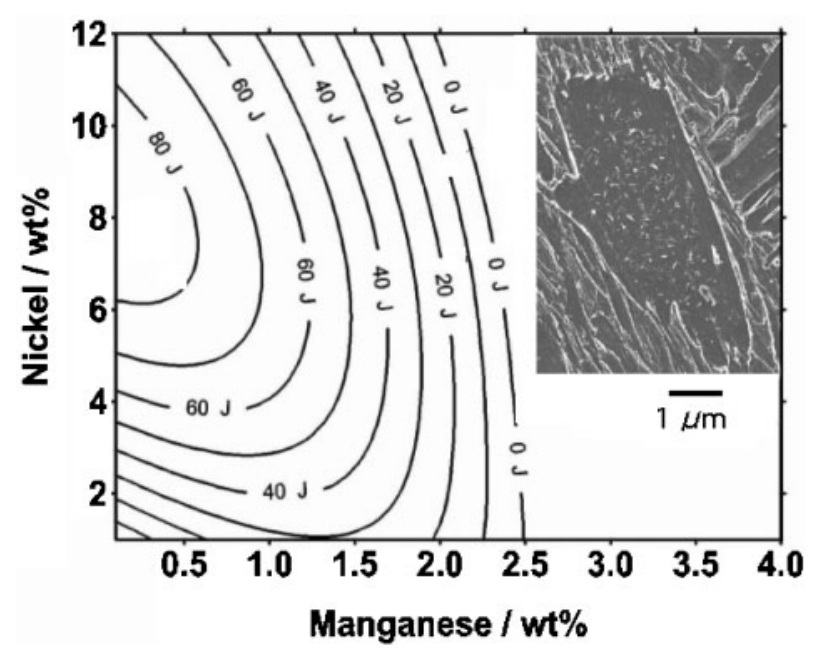

3 Contours showing calculated combined effect of manganese and nickel on calculated toughness for $-60^{\circ} \mathrm{C}$, of ferritic weld metal: inset shows the coarse, coalesced bainite which is responsible for deterioration in toughness as nickel is added to weld already containing substantial concentration of managanese $\mathrm{e}^{29-31}$

the bainite start and martensite start temperature diminishes, it is possible to generate very coarse regions of coalesced-bainite which are bad for toughness.

It is unlikely that the existence of this detrimental phase in high strength steel weld deposits would have been revealed without the creation of a neural network model which uncompromisingly accounts for the full range of variables that influence the Charpy toughness and which can be examined quantitatively to reveal patterns.

\section{Assessment of performance}

On the basis of the preceding discussion, the authors now proceed to assess a range of publications on neural networks, focusing on a limited number of publications over the period 2005-7, but selecting others on an ad hoc basis in order to illustrate the method. The purpose of this exercise is to highlight the optimum method for presenting neural network models such that the well established principles of scientific publishing are respected while at the same time, the models pay proper respect to uncertainties and dissemination.

The marking scheme is presented in Table 1. The first achievement is of course to do the work necessary to assemble the data and to create a network. Such a network must be considered potentially unreliable unless its behaviour and predictions are explored, both within the domain of the training data and beyond. The term

Table 1 Marking scheme for models

\begin{tabular}{ll}
\hline Characteristic & Mark \\
\hline Model or data disseminated & 3 \\
Modelling uncertainty & 2 \\
Prediction investigated experimentally & 2 \\
Predictions made and interpreted & 2 \\
Model created & 1 \\
\hline
\end{tabular}

Prediction refers to using the model in a regime of inputs not included in the data used to create the model; a model refers to a transparent mathematical function and associated coefficients; dissemination implies making the model available to others.
Table 2 Results of assessment

\begin{tabular}{lll}
\hline Mark & No. of papers & Reference no. \\
\hline 10 & 1 & {$[15]$} \\
8 & 6 & {$[13,35-39]$} \\
7 & 1 & {$[40]$} \\
6 & 1 & {$[41]$} \\
5 & 5 & {$[42-47]$} \\
3 & 20 & {$[16,19,37,48-64]$} \\
1 & 66 & {$[65-130]$} \\
\hline
\end{tabular}

'prediction' in this context means conducting calculations in a regime where data do not exist.

The trends revealed by the network should be interpreted in terms of the known science of the problem. It is possible that a network captures false correlations and these can render it unsafe in application.

Some of the predictions of the network may be usefully investigated by conducting specific experiments. As described in the earlier part of this paper, such investigations may lead to novel materials science.

It is important to realise that the extrapolation of a network cannot be satisfactorily explored without an indication of modelling uncertainty. In a non-linear model, extrapolation cannot be defined as being out of the range of the training data unless the latter are absolutely uniformly distributed in the input space. Modelling uncertainty, however it is calculated, must be considered an essential feature of neural networks.

Finally, for reasons already discussed, the dissemination of the model or data is vital for scientific progress and independent verification.

Our assessment of publications in this context is listed in Table 2. It is evident that the majority of models are not disseminated, meaning that the resulting papers are of use mostly to their authors. It is surprising that many attempts at neural network modelling do not include the exploration of the model as described above. Similarly, there is little consideration of modelling uncertainties.

\section{Summary}

Neural networks have had a significant impact on the development of materials and associated processes. This is because they represent a transparent and quantitative method which is able to deal with sophisticated problems typical in materials science.

It is obvious, however, that to exploit the full potential of the technique, it is necessary to think about the best method for publishing the results, with particular attention being paid to dissemination and modelling uncertainties. Neither of these is difficult to achieve.

It is important also to study the behaviour of the network in domains where knowledge does not exist, i.e. to use the models to make bold predictions which form the basis for experiments and the discovery of new phenomena. Indeed, the performance of a network is most useful to researchers in domains where the modelling uncertainty is greatest. An alternative way of stating this is that new experiments are only necessary when the network predicts that the uncertainty is large.

\section{References}

1. D. J. C. MacKay: 'Information theory, inference, and learning algorithms'; 2003, Cambridge, Cambridge University Press. 
2. D. J. C. MacKay: Neural Comput., 1992, 4, 448-472.

3. B. G. Sumpter and D. W. Noid: Annu. Rev. Mater. Sci., 1996, 26, 223-277.

4. H. K. D. H. Bhadeshia: ISIJ Int., 1999, 39, 966-979.

5. Z. Sterjovski, D. Nolan, K. Carpenter, D. Dunne and J. Norrish J. Mater. Process. Technol., 2005, 170, 536-544.

6. H. K. D. H. Bhadeshia: Mater. Sci. Technol., 2008, 24, 128-135.

7. R. J. Abrahart, A. J. Heppenstall and L. M. See: Hydrol. Sci. 2007, 52, 414 432 .

8. H. R. Maier and G. C. Dandy: Environ. Modell. Software, 2000 15, 101-124.

9. M. W. Gardner and S. R. Dorling: Atmosph. Environ., 2000, 32, 2627-2636.

10. H. Adeli: Comput.-Aided Civil Infrastruct. Eng., 2001, 16, 126 142.

11. A. B. Bulasari: J. Syst. Eng., 1994, 4, 131-170.

12. R. D. Vanluchene and R. Sun: Microcomput. Civil Eng., 1990, 5, 207-215.

13. R. Kemp, G. A. Cottrell, H. K. D. H. Bhadeshia, G. R. Odette, T. Yamamoto and H. Kishimoto: J. Nucl. Mater., 2006, 348, 311 328.

14. H. K. D. H. Bhadeshia: Mater. Sci. Technol., 2008, 24, 128-135.

15. S. Chatterjee, M. Murugananth and H. K. D. H. Bhadeshia: Mater. Sci. Technol., 2007, 23, 819-827.

16. A. Chaudhury, R. Kahtirkar, N. N. Viswanathan, V. Singhal, A. Ingle, S. Johsi and I. Samajdar: J. Magn. Magn. Mater., 2007, 313, 21-28.

17. T. Zacharia, J. M. Vitek, J. A. Goldak, T. A. DebRoy, M. Rappaz and H. K. D. H. Bhadeshia: Modell. Simul. Mater. Sci. Eng., 1995, 3, 265-288.

18. G. E. Ridings, R. C. Thomson and G. Thewlis: Sci. Technol. Weld., 2002, 7, 265-279.

19. S. Mishra and T. DebRoy: Mater. Sci. Eng. A, 2007, A454, 477486.

20. C. A. Santos, E. L. Fortaleza, C. R. F. Ferreira, J. A. Spim and A. Garcia: Modell. Simul. Mater. Sci. Eng., 2005, 13, 1071-1087.

21. F. Brun, T. Yoshida, J. D. Robson, V. Narayan, H. K. D. H Bhadeshia and D. J. C. MacKay: Mater. Sci. Technol., 1999, 15, 547-554.

22. D. Cole, C. Martin-Moran, A. Sheard, H. K. D. H. Bhadeshia and D. J. C. MacKay: Sci. Technol. Weld. Join., 2000, 5, 81-89.

23. H. K. D. H. Bhadeshia: ISIJ Int., 2001, 41, 621-640.

24. M. Murugananth and H. K. D. H. Bhadeshia: in 'Mathematical modelling of weld phenomena 6', (ed. H. Cerjak and H. K. D. H. Bhadeshia), 243-260; 2002, London, Maney.

25. M. Murugananth: 'Design of welding alloys for creep and toughness', PhD thesis, University of Cambridge, Cambridge, UK, 2002.

26. S. H. Lalam, H. K. D. H. Bhadeshia and D. J. C. MacKay: Sci. Technol. Weld. Join., 2000, 5, 135-147.

27. S. H. Lalam, H. K. D. H. Bhadeshia and D. J. C. MacKay: Sci. Technol. Weld. Join., 2000, 5, 149-160.

28. M. Murugananth, S. S. Babu and S. A. David: Weld. J., Res. Suppl., 2004, 85, 267s-276s.

29. M. Murugananth, H. K. D. H. Bhadeshia, E. Keehan, H. O Andren and L. Karlsson: in 'Mathematical modelling of weld phenomena 6', (ed. H. Cerjak and H. K. D. H. Bhadeshia), 205230; 2002, London, Maney.

30. E. Keehan, H.-O. Andren, L. Karlsson, M. Murugananth and H. K. D. H. Bhadeshia: in 'Trends in welding research', (ed. S. A David and T. DebRoy), 695-700; 2002, Materials Park, OH, ASM.

31. E. Keehan, L. Karlsson and H.-O. Andren: Sci. Technol. Weld. Join., 2006, 11, 1-8.

32. E. Keehan, L. Karlsson, H.-O. Andren and H. K. D. H. Bhadeshia: Sci. Technol. Weld. Join., 2006, 11, 9-18.

33. E. Keehan, L. Karlsson, H.-O. Andren and H. K. D. H Bhadeshia: Sci. Technol. Weld. Join., 2006, 11, 19-24.

34. H. K. D. H. Bhadeshia: Trans. Ind. Inst. Met., 2006, 59, 689-694.

35. T. Cool, H. K. D. H. Bhadeshia and D. J. C. MacKay: Mater. Sci. Eng. A, 1997, A223, 186-200.

36. S. B. Singh, H. K. D. H. Bhadeshia: Mater. Sci. Eng. A, 1998, A245, 72-79.

37. S. Chatterjee and H. K. D. H. Bhadeshia: Mater. Sci. Technol., 2007, 23, 606-609.

38. R. Dimitriu and H. K. D. H. Bhadeshia: Mater. Sci. Technol., 2007, 23, 1127-1131.

39. S. Das: 'Bake hardening steels', unpublished work, 2007.

40. J. Tenner, D. A. Linken, P. F. Morris and T. J. Bailey: Ironmaking Steelmaking, 2001, 28, 15-22.
41. T. Sourmail and C. Garcia-Mateo: Comput. Mater. Sci., 2005, 34, (4), 323-334.

42. M. Mukherjee, S. B. Singh and O. N. Mohanty: Mater. Sci. Eng. A, 2006, A434, 237-245.

43. J. Mirapeix, P. B. Garcia-Allende, A. Cobo, O. M. Conde and J. M. Lopez-Higuera: NDT E Int., 2007, 40, 315-323.

44. D. V. Raju, A. Iqbal, A. K. Trivedi and A. Mukhopadhyay: Ironmaking Steelmaking, 2007, 34, 166-176.

45. M. Mukherjee, S. B. Singh and O. N. Mohanty: Mater. Sci. Technol., 2007, 23, 338-346.

46. T. Kwak, T. Suzuki, W. Bae, Y. Uehara and H. Ohmori: J. Mater. Process. Technol., 2005, 170, (1-2), 24-31.

47. H. K. D. H. Bhadeshia, D. J. C. MacKay and L.-E. Svensson: Mater. Sci. Technol., 1995, 11, 1046-1051.

48. K. Y. Su and K. B. Tak: J. Geotech. Geoenviron. Eng., 2006, 132, $1502-1504$.

49. A. Sozen, M. Ozalp and E. Arcaklioglu: Appl. Therm. Eng., 2006, 27, 551-559.

50. Y. S. Murat and H. Ceylan: Energy Policy, 2006, 34, 3165-3172.

51. F. Inal: Fuel Process. Technol., 2006, 87, 1031-1036.

52. R. Huang, L. Xi, X. Li, C. R. Liu, H. Qiu and J. Lee: Mech. Syst. Signal Process., 2006, 21, 193-207.

53. Y. Kang, C. C. Huang, C. S. Lin, P. C. Shen and Y. P. Chang: Tribol. Int., 2006, 39, 461-469.

54. M. Vasudevan, A. K. Bhaduri, B. Raj and K. P. Rao: Mater. Sci. Technol., 2007, 23, 451-459.

55. L. J. Xu, J. D. Xing, S. Z. Wei, Y. Z. Zhang and R. Long: Mater. Sci. Technol., 2007, 23, 315-319.

56. K. Patra, S. K. Pal and K. Bhattacharyya: Appl. Soft Comput., 2007, 7, 929-935.

57. V. Diaz and C. Lopez: Corros. Sci., 2007, 49, 949-962.

58. M. Pala and N. Caglar: J. Constr. Steel Res., 2007, 63, 686-691.

59. P. Dutta and D. K. Pratihar: J. Mater. Process. Technol., 2007, 184, 56-68.

60. M. Vasudevan, B. Rao, B. Venkatraman, T. Jayakumar and B. Raj: J. Mater. Process. Technol., 2005, 169, 396-400.

61. N. Reddy, A. P. Rao, M. Chakraborty and B. Murty: Mater. Sci. Eng. A, 2005, A391, (1-2), 131-140.

62. S. Curcio, G. Scilingo, V. Calabro and G. Iorio: J. Membr. Sci., 2005, 246, (2), 235-247.

63. P. J. Laitinen and H. Saxen: Ironmaking Steelmaking, 2007, 34, 109-114.

64. A. Kermanpur, A. Ebnonnasir and M. Hedayati: Mater. Sci. Technol., 2007, 23, 951-957.

65. M. P. Lightfoot, N. A. McPherson, K. Woods and G. J. Bruce: J. Mater. Process. Technol., 2006, 172, 238-242.

66. I. H. Guzelbey, A. Cevik and A. Erklig: J. Constr. Steel Res., 2006, 62, 962-973.

67. G. B. Sahoo, C. Ray, E. Mehnert and D. A. Keefer: Sci. Total Environ., 2006, 367, 234-251.

68. A. Mandal and P. Roy: J. Mater. Process. Technol., 2006, 180, $167-173$

69. F. Karimzadeh, A. Ebnonnasir and A. Foroughi: Mater. Sci. Eng. A, 2006, A432, 184-190.

70. Y. C. Chang: Build. Environ., 2006, 42, 180-188.

71. H. Cetinel, H. Ozturk, E. Celik and B. Karlik: Wear, 2006, 261, $1064-1068$

72. S. D. Walters, M. M. D. Zoysa and R. J. Howlett: Meas. Sci. Technol., 2006, 17, 2773-2782.

73. M. Moosavi, M. J. Yazdanpanah and R. Doostmohammadi: Eng. Geol., 2006, 87, 178-194.

74. A. P. Vassilopoulos, E. F. Georgopoulos and V. Dionysopoulos: Int. J. Fatigue, 2006, 29, 20-29.

75. D. Bas, F. C. Dudak and I. H. Boyaci: J. Food Eng., 2006, 79, $1152-1158$.

76. J. Shi, X. Liu and Y. Sun: Neurocomputing, 2006, 79, 280-287.

77. S. Guessasma, M. Bounazef and P. Nardin: Int. J. Refract. Met. Hard Mater., 2006, 24, 240-246.

78. P. G. Benardos, S. Mosialos and G. C. Vosniakos: Robot. Comput.-Integr. Manuf., 2006, 22, 505-514.

79. I. H. Guzelbey, A. Cevik and M. T. Gogus: J. Constr. Steel Res., 2006, 62, 950-961.

80. L. D. Graham, D. R. Forbes and S. D. Smith: Autom. Constr., 2006, 15, 656-663.

81. A. G. Olabi, G. Casalino, K. Y. Benyounis and M. S. J. Hashmi: Adv. Eng. Software, 2006, 37, 643-648.

82. M. A. Yurdusev, R. Ata and N. S. Cetin: Energy, 2006, 31, 2153 2161.

83. H. T. Pao: Energy, 2006, 31, 2129-2141. 
84. W. Hao, X. Zhu, X. Li and G. Turyagyenda: J. Mater. Process Technol., 2006, 180, 23-29.

85. S. Jain and M. M. Ali: IEE Geosci. Remote Sens. Lett., 2006, 3, $467-470$.

86. A. A. Carvalho, J. M. A. Rebello, L. V. S. Sagrilo, C. S. Camerini and I. V. J. Miranda: NDT E Int., 2006, 39, 661-667.

87. K. Kuzniar and Z. Waszczyszyn: J. Comput. Civil Eng., 2006, 20, 431-436.

88. D. A. Axinte: Int. J. Mach. Tools Manuf., 2006, 46, 1445-1448.

89. D. J. Lee and S. S. Cha: Opt. Eng., 2006, 45, 107202-1-107202-8.

90. A. Sencan: Renew. Energy, 2006, 32, 314-328.

91. H. Kawabe, N. Tsukiyama and K. Yoshida: Mater. Sci. Eng. A, 2006, A442, 547-550.

92. M.-X. Zhang and P. M. Kelly: Mater. Sci. Eng. A, 2006, A438 A440, 272-275.

93. J. Jia and J. F. Davalos: Compos. Struct., 2006, 74, 106-114.

94. M. A. Salam, S. M. Al-Alawi and A. A. Maqrashi: J. Electrostat., 2006, 64, 338-342.

95. N. R. Nene, A. Vieira and N. P. Barradas: NIMB Beam Interact. Mater. Atoms, 2006, 246, 471-478.

96. S. Datta and M. K. Banerjee: Mater. Sci. Eng. A, 2006, A420, 254-264.

97. L. Qiang, Y. J. Yuan, M. B. Chun and S. X. Dong: Mater. Sci. Eng. A, 2006, A419, 214-217.

98. H. J. Zhang, X. J. Wang, Q. L. Jia and H. W. Sun: Mater. Sci. Technol., 2007, 23, 1021-1026.

99. C. Sanjay, M. Neema and C. Chin: J. Mater. Process. Technol., 2005, 170, (3), 494-500.

100. Z. Sterjovski, D. Nolan, K. Carpenter, D. Dunne and J. Norrish J. Mater. Process. Technol., 2005, 170, (3), 536-544.

101. A. Zhecheva, S. Malinov and W. Sha: Surf. Coat. Technol., 2005, 7, 2332-2334

102. A. Bahrami, S. M. Anijdan, H. M. Hosseini, A. Shafyei and R. Narimani: Comput. Mater. Sci., 2005, 34, (4), 335-341.

103. H. Luo, H. Zeng, L. Hu, X. Hu and Z. Zhou: J. Mater. Process. Technol., 2005, 170, (1-2), 403-411.

104. P. Laurinen and J. Rning: J. Mater. Process. Technol., 2005, 168 (3), 423-430.

105. T. Parthiban, R. Ravi, G. Parthiban, S. Srinivasan, K. Ramakrishnan and M. Raghavan: Corros. Sci., 2005, 47, (7), 1625-1642.

106. Z. Guo, S. Malinov and W. Sha: Comput. Mater. Sci., 2005, 32, (1), $1-12$.

107. S. Bruschi, S. Casotto, T. D. Negro and P. F. Bariani: CIRP Ann, Manuf. Technol., 2005, 54, (1), 229-232.
108. I. S. Kim, J. S. Son, C. E. Park, I. J. Kim and H. H. Kim: J Mater. Process. Technol., 2005, 159 (1), 113-118.

109. J. Trzaska and L. Dobrzanski: J. Mater. Process. Technol., 2005, 164-165, 1637-1643.

110. J.-S. Son, D.-M. Lee, I.-S. Kim and S.-G. Choi: J. Mater. Process. Technol., 2005, 164-165, 1612-1617.

111. A. Bahrami, S. M. Anijdan and A. Ekrami: J. Alloys Compd, 2005, 392, (1-2), 177-182.

112. L. Dobrzanski, M. Kowalski and J. Madejski: J. Mater. Process. Technol., 2005, 164-165, 1500-1509.

113. N. Altinkok and R. Koker: Mater. Des., 2005, 26, (4), 305-311.

114. S. M. Anijdan and A. Bahrami: Mater. Sci. Eng. A, 2005, A396, (1-2), 138-142.

115. R.-Q. Fu, T.-W. Xu and Z.-X. Pan: J. Membr. Sci., 2005, 251, (12), 137-144.

116. M. Moliner, J. Serra, A. Corma, E. Argente, S. Valero and V. Botti: Micropor. Mesopor. Mater., 2005, 78, (1), 73-81.

117. D. Chakraborty: Mater. Des., 2005, 26, (1), 1-7.

118. L. Dobrzanski, M. Drak and J. Trzaska: J. Mater. Process. Technol., 2005, 164-165, 795-804.

119. M.-D. Jean, C.-D. Liu and J.-T. Wang: Appl. Surf. Sci., 2005, 245, (1-4), 290-303.

120. O. E. R. Hamzaoui, S. Guessasma and E. Gaffet: Mater. Sci. Eng. $B, 2005$, B119, (2), 164-170.

121. K. Song, J. Xing, Q. Dong, P. Liu, B. Tian and X. Cao: Mater. Des., 2005, 26, (4), 337-341.

122. F. Tymvios, C. Jacovides, S. Michaelides and C. Scouteli: Solar Energy, 2005, 78, (6), 752-762.

123. C. Aydiner, I. Demir and E. Yildiz: J. Membr. Sci., 2005, 248, (12), 53-62.

124. T. Islam, C. Pramanik and H. Saha: Microelectron. Reliab., 2005, 45, (3-4), 697-703.

125. M. Cherigui, S. Guessasma, N. Fenineche and C. Coddet: Mater. Sci. Eng. B, 2005, B116, (1), 40-46.

126. W.-Z. Cui, C.-C. Zhu and H.-P. Zhao: Thin Solid Films, 2005, 473, (2), 224-229.

127. N. Fenineche, S. Guessasma and N. Abdelbaki: Mater. Sci. Eng. $B, 2005$, B119, (1) 65-70.

128. C. Negro, A. Alonso, A. Blanco and J. Tijero: Compos. Part A, Appl. Sci. Manuf., 2005, 36A, (12), 1617-1626.

129. X. He, X. Zhang, S. Zhang, J. Liu and C. Li: Fluid Phase Equilib., 2005, 238, (1), 52-57.

130. J. R. Smith, V. Kholodovych, D. Knight, J. Kohn and W. J. Welsh: Polymer, 2005, 46, (12), 4296-4306. 